\title{
A test of baker's law: breeding systems of invasive species of Asteraceae in China
}

\author{
Jian H. Hao - Sheng Qiang • Thomas Chrobock • \\ Mark van Kleunen - Qian Q. Liu
}

\begin{abstract}
Invasive alien plant species are frequently characterized by a high fecundity. However, because suitable pollinators and/or mates may be absent in the new range, it is not clear how they achieve high seed production. According to Baker's Law, species capable of uniparental reproduction are more likely to establish after long-distance dispersal than species that rely on suitable mates and pollinators. To test whether selfcompatible species, and particularly species capable of autonomous seed set, are more likely to establish and spread, we experimentally assessed the breeding systems of 12 species of Asteraceae that are invasive in China. Among these 12 species of Asteraceae, the percentages of self-compatible species $(66.7 \%)$ and species capable of autonomous seed set $(83.3 \%)$, which included self-fertilizing and apomictic species, were
\end{abstract}

Electronic supplementary material The online version of this article (doi:10.1007/s10530 0109850 4) contains supplementary material, which is available to authorized users.

J. H. Hao · S. Qiang ( $₫) \cdot$ Q. Q. Liu

Weed Research Laboratory, Nanjing Agricultural

University, 210095 Nanjing, China

e mail:wrl@njau.edu.cn

J. H. Hao

College of Biology and Food Engineering, Changshu

Institute of Technology, 215500 Changshu, China

T. Chrobock $\cdot$ M. van Kleunen

Institute of Plant Sciences, University of Bern,

Altenbergrain 21, 3013 Bern, Switzerland significantly larger than expected from the percentages of such species in global data sets of Asteraceae $(36.8 \%$ and $46.0 \%$, respectively). Furthermore, the number of Chinese provinces in which the invasive alien species occur was significantly positively correlated with the proportion seed set on bagged capitula (i.e. with the degree of autonomous seed set). Among 36 species of Asteraceae that are invasive in China and for which we found breeding-system data in the literature, we also found a higher than expected percentage of selfcompatible species $(65.7 \%)$, and that these self-compatible species are more widespread in China than self-incompatible species. These results support the predictions of Baker's Law that self-compatible species, and particularly those capable of autonomous seed production, are more likely to establish and spread in a new range. Therefore, breeding systems of plants should be included as one of the key elements in risk assessment protocols for plant invasiveness.

Keywords Asteraceae - Agamospermy - Apomixis . Autonomous seed production - Baker's rule . Breeding system · Invasiveness - Self-compatiblity

\section{Introduction}

Biological invasions pose a threat to biodiversity and ecosystem functioning, and can have large economic costs (Mooney et al. 2005). Therefore, one of the major aims in invasion biology is to find species 
attributes that contribute to invasiveness and can be used to inform risk assessment (Daehler and Strong 1993; Rejmánek 1996; Rejmánek and Richardson 1996; Groves et al. 2001; Daehler 2003; Richardson and Pyšek 2006; van Kleunen and Richardson 2007). Obviously, introduced alien species can only become invasive if they manage to reproduce (Richardson et al. 2000). Indeed, high fecundity is frequently associated with invasive alien plant species (Pyšek and Richardson 2007; Mason et al. 2008; van Kleunen et al. 2010). However, it is less clear how invasive alien plants achieve a high reproductive output, particularly because they may lack suitable pollinators and/or suitable mates in the new range.

Baker (1955) pointed out that species capable of uniparental reproduction should be more likely to establish after long-distance dispersal than species that rely on suitable mates and pollinators. Therefore, self-compatible species, which do not suffer from mate limitation, and particularly species capable of autonomous seed set, which do not suffer from mate and pollinator limitation, are likely to be superior colonizers. This hypothesis, which is better known as Baker's Law (Stebbins 1957; also frequently referred to as Baker's rule), is likely to apply to both the initial establishment of alien plants after a long-distance dispersal event and to their subsequent spread in a new range (see Pannell and Barrett 1998; van Kleunen and Johnson 2005). Even in the presence of suitable mates and pollinators, autonomous selffertilization might increase seed production (e.g. Rodger et al. 2010), and therefore, result in higher propagule pressure and invasiveness (e.g., Lockwood et al. 2005; Colautti et al. 2006).

Several multi-species studies have shown that autonomous seed production is frequently associated with naturalized and invasive plant species (Rambuda and Johnson 2004; van Kleunen and Johnson 2007; van Kleunen et al. 2008). Nevertheless, because there are also examples of highly invasive self-incompatible species, such as Centaurea solstatilis (Sun and Ritland 1998), Senecio squalides (Brennan et al. 2002), Mikania micrantha (Hong et al. 2007) and Senecio inaequidens (Lafuma and Maurice 2007), and highly invasive dioecious species (Cronk and Fuller 2001), there is still considerable skepticism regarding the applicability of Baker's Law to plant invasions. Therefore, we need more studies, particularly on multiple species, before we can conclude that self-compatibility and the ability for autonomous seed reproduction are generally associated with invasiveness.

We experimentally assessed the breeding systems of 12 species of Asteraceae that are invasive in China. In addition, we compiled breeding system data of 36 such species from the literature. We chose the Asteraceae, because it is the largest dicotyledonous family and because it is notorious for its invasive species (Wu and Wang 2005; Zhu et al. 2005). Species of Asteraceae are proportionally overrepresented among invasive plant species worldwide (Pyšek 1998; but see Daehler 1998). Particularly in China, the percentage of invasive species of Asteraceae (c. 20\%; Xu and Qiang 2004; Weber et al. 2008) is much larger than the percentage of Asteraceae in the global flora (8.4\%; Pyšek 1998). Moreover, although most tribes of Asteraceae have both self-compatible and self-incompatible taxa (Ferrer and Good-Avila 2007), a minority of Asteraceae at least the ones with known breeding systems are fully or partially self-compatible $(36.8 \%$; Ferrer and Good-Avila 2007 ), and less than half $(46.0 \%)$ are capable of autonomous seed set (including autogamous and apomictic species; Fryxell 1957). Thus, if self-compatibility and autonomous seed set are prevalent among invasive species of Asteraceae, this would be strong support for Baker's Law.

We used the breeding-system data of Asteraceae to address the following specific questions. (1) Is selfcompatibility and ability for autonomous seed set among invasive Asteraceae in China more frequent than predicted from global breeding-system data of Asteraceae? (2) Is size of the invaded range positively associated with the degree of autonomous seed set among the invasive Asteraceae in China? We discuss the importance of our findings for the development of risk-assessment protocols for invasiveness.

\section{Materials and methods}

Study species and plant material

In China, 44 (Xu and Qiang 2004) to 53 (Weber et al. 2008) species of Asteraceae are considered invasive. These invasive species occur predominantly in urban and rural areas, but most of them also invade natural habitats, and cause damage to native species, habitats, 
or to the economy (Weber et al. 2008). We selected all invasive species of Asteraceae that we could find near the city of Nanjing in the Jiangsu province of China, which resulted in 11 species. In addition, we selected Ageratina adenophora, which is invasive in the south-western parts of China, because we had it growing in our greenhouse. The 12 species differ in their regions of origin, life-form and range size in China (Table 1). Although for most of these species some information on their breeding systems is already available in the literature (Table 1), the ability for autonomous seed set was unknown for most of the 12 species.

In the springs of 2005 and 2006, we excavated 635 plants of each species from naturalized populations near Nanjing (except for A. adenophora, which we had already in our greenhouse), transplanted them into pots, and placed them in a greenhouse of the Nanjing Agricultural University. The greenhouse was open on all sides, which allowed access of pollinators to the plants. We watered the plants as needed.

\section{Breeding-system assessment}

To test whether our 12 study species are capable of autonomous seed set, we excluded pollinators from flowers by enclosing several capitula on each plant in paper bags. To test for non-pseudogamous apomixis (agamospermy), we cut off all anthers and stigmas of several capitula on each plant during the bud stage. As controls, we left several capitula on each plant for open pollination. We used five to 32 plants per species (Table 1), and each treatment included 670 capitula per species (more information on sample sizes per treatment and per species are given in Appendix S1 Electronic supplementary material). Experiments on the species were done in the years 2005, 2006 or 2008. For two of the species, $C$. sumatrensis and $S$. asper, we did the experiments in 2 years. We calculated seed set as the proportion of florets in a capitulum that developed achenes. If necessary, we used a dissecting microscope to assess whether achenes had developed.

Because species that are not capable of autonomous seed production could nevertheless be self-compatible, we tested self-pollen-stigma compatibility for seven of the 12 species (Table 1). The self-incompatibility response of Asteraceae usually takes place at the stigmatic surface, and in an incompatible pollenstigma interaction, pollen grains do not germinate or growth of pollen tubes is arrested at the stigmatic surface (Hiscock 2000). For each of the seven species, we collected two to three flowering capitula that had been enclosed in paper bags since the bud stage to prevent cross-pollination. We examined the germination of self-pollen grains and growth of their pollen tubes using the aniline-blue-fluorescence microscopy method (Currier 1957).

We considered a species as capable of autonomous seed production if it produced seeds on bagged capitula. In case a species capable of autonomous seed production also produced seeds on decapitated capitula, we considered it as apomictic, and otherwise as autogamous. The latter automatically means that the species is self-compatible. Because our breedingsystem experiments did not include selfing and outcrossing treatments, which are virtually impossible in Asteraceae, we could not assess whether selfing results in similar levels of seed production as outcrossing, and also not whether genotypes of a species differ in self-compatibility. Therefore, we did not differentiate between fully and partially selfcompatible species. For species not capable of autonomous seed production (and also for apomictic species), we considered them as self-incompatible if self-pollen did not germinate or if pollen tubes did not grow into the style.

Because our sample of 12 species might not be representative for all 44 (Xu and Qiang 2004) or 53 (Weber et al. 2008) species of Asteraceae considered invasive in China, we additionally compiled breeding-system data from the literature for as many of these species as possible. This resulted in breedingsystem data for 36 invasive species of Asteraceae in China (Appendix S2 Electronic supplementary material).

\section{Statistical analyses}

To test whether average seed set per capitulum per plant differed significantly at $P<0.05$ between open-pollinated, bagged and decapitated treatments, we used Tukey's multiple-comparison tests for each species separately (statistical software: JMP 7.0; SAS Institute Inc., Cary, NC, USA).

To test whether the frequencies of self-compatible species among the 12 invasive Asteraceae in China used 
Table 1 The 12 species of Asteraceae that are invasive in China, and were used in our breeding-system experiments

\begin{tabular}{|c|c|c|c|c|c|c|c|}
\hline Species & Life form & Native range & $\begin{array}{l}\text { Range } \\
\text { size in } \\
\text { China }^{\text {b }}\end{array}$ & $\begin{array}{l}\text { No. of } \\
\text { plants in } \\
\text { experiment }\end{array}$ & $\begin{array}{l}\text { Inferred breeding } \\
\text { system }\end{array}$ & $\begin{array}{l}\text { Breeding system } \\
\text { reported in literature }\end{array}$ & Reference $^{\mathrm{d}}$ \\
\hline $\begin{array}{l}\text { Ageratina adenophora }^{\text {a }} \\
\text { (Eupatorium } \\
\text { adenophorum) }\end{array}$ & Perennial shrub & Mexico & 8 & 10 & $\begin{array}{l}\text { Self-incompatible, } \\
\text { apomixis }\end{array}$ & Apomixis & $1,2,3,4,5$ \\
\hline Ageratum conyzoides & Annual & $\begin{array}{l}\text { South and Central } \\
\text { America }\end{array}$ & 24 & 29 & $\begin{array}{l}\text { Self-compatible, } \\
\text { autogamous, } \\
\text { some apomixis }\end{array}$ & $\begin{array}{l}\text { Self-compatible, } \\
\text { self-incompatible, } \\
\text { some apomixis }\end{array}$ & $5,6,7,8$ \\
\hline Aster subulatus & Annual & North America & 20 & 11 & $\begin{array}{l}\text { Self-compatible, } \\
\text { autogamous. }\end{array}$ & - & \\
\hline Bidens pilosa $a^{\mathrm{a}}$ & Annual & Tropical America & 22 & 10 & $\begin{array}{l}\text { Self-compatible, } \\
\text { autogamous }\end{array}$ & Self-compatible & $5,7,9$ \\
\hline Conyza bonariensis & $\begin{array}{l}\text { Annual or winter- } \\
\text { annual }\end{array}$ & South America & 21 & 5 & $\begin{array}{l}\text { Self-compatible, } \\
\text { autogamous }\end{array}$ & - & 5 \\
\hline Conyza canadensis & $\begin{array}{l}\text { Annual or winter- } \\
\text { annual }\end{array}$ & North America & 34 & 10 & $\begin{array}{l}\text { Self-compatible, } \\
\text { autogamous }\end{array}$ & Self-compatible & $5,10,11$ \\
\hline Conyza sumatrensis & $\begin{array}{l}\text { Annual or winter- } \\
\text { annual }\end{array}$ & South America & 21 & $15,32^{\mathrm{c}}$ & $\begin{array}{l}\text { Self-compatible, } \\
\text { autogamous }\end{array}$ & Self-compatible & 12 \\
\hline Coreopsis lanceolata $^{\mathrm{a}}$ & Perennial herb & North America & 13 & 12 & Self-incompatible & - & 5 \\
\hline Erigeron annuus $^{\mathrm{a}}$ & $\begin{array}{l}\text { Annual or winter- } \\
\text { annual }\end{array}$ & North America & 31 & 11 & $\begin{array}{l}\text { Self-incompatible, } \\
\text { apomixis }\end{array}$ & Apomixis & $3,13,14$ \\
\hline Solidago canadensis ${ }^{\mathrm{a}}$ & Perennial herb & North America & 14 & 14 & Self-incompatible & $\begin{array}{l}\text { Self-incompatible or } \\
\text { partial self- } \\
\text { incompatible }\end{array}$ & $\begin{array}{c}5,10,13,15,16 \\
17\end{array}$ \\
\hline Sonchus asper ${ }^{a}$ & $\begin{array}{l}\text { Annual or winter- } \\
\text { annual }\end{array}$ & Europe & 34 & $13,10^{\mathrm{c}}$ & $\begin{array}{l}\text { Self-compatible, } \\
\text { autogamous }\end{array}$ & Self-compatible & $5,18,19,20$ \\
\hline Sonchus oleraceus ${ }^{\mathrm{a}}$ & $\begin{array}{l}\text { Annual or winter- } \\
\text { annual }\end{array}$ & Europe & 34 & 11 & $\begin{array}{l}\text { Self-compatible, } \\
\text { autogamous }\end{array}$ & $\begin{array}{l}\text { Self-compatible } \\
\text { or self-incompatible }\end{array}$ & $5,17,18,19$ \\
\hline
\end{tabular}

The table reports for each species the life form, the native range, the size of the invaded range in China, the number of plants used in the breeding-system experiment, the breeding system inferred from our experiments, and the breeding system of the species that were reported in the literature

a These seven species were also included in the tests for self-pollen-stigma compatibility

b Range size of a species was measured as number of invaded provinces in China, which also includes Taiwan and the special administrative region of Hong Kong and Macao (total is 34)

c The breeding system experiments on Conyza sumatrensis and Sonchus asper were done in 2 years with different sample sizes

d References 1, Baker 1965; 2, Auld and Martin 1975; 3, Nogler 1984; 4, Rambuda and Johnson 2004; 5, Ferrer and Good-Avila 2007; 6, Pullaiah 1982; 7, McMullen 1987; 8 ,

Ming 1999; 9, Grombone-Guaratini et al. 2004; 10, Mulligan and Findlay 1970; 11, Weaver 2001; 12, Hao et al. 2009; 13, Fryxell 1957; 14, Noyes and Rieseberg 2000; 15,

Werner et al. 1980; 16, Melvillme and Morton 1982; 17, Bertin 1993; 18, Hutchinson et al. 1984; 19, Mejias 1992; 20, Van Kleunen and Johnson 2007 
in our breeding-system experiments and among the 36 invasive Asteraceae in China for which we found breeding-system data in the literature are larger than expected, we compared them to the frequency of selfcompatible species in a data set of 571 species of Asteraceae from around the world (Ferrer and GoodAvila 2007). To the best of our knowledge, this is the largest data set on self-compatibility of Asteraceae that is available. This data set does not give information on the ability for autonomous seed set (i.e. autogamy and apomixis) of species. Therefore, to test whether the frequency of species with autonomous seed set among our 12 species of Asteraceae that are invasive in China is larger than expected, we compared it to the frequency of species with potential for autonomous seed set in a data set of 139 species of Asteraceae from around the world (Fryxell 1957; also see Rambuda and Johnson 2004). A similar analysis was not possible for the 36 invasive Asteraceae in China for which we collected breedingsystem data from the literature, because for most of these species we had no information on autonomous seed set. Fryxell (1957) categorized breeding systems of species within a triangle between strictly self-incompatible, strictly apomictic and strictly autogamous. The latter two categories are capable of autonomous seed set, but also some of the intermediate categories in Fryxell's classification system might be capable of this. Therefore, we categorized all species that are not strictly selfincompatible in Fryxell's data set as species with autonomous seed set. This is most likely an overestimate, which makes our comparison more conservative. We tested the significance of deviations of frequencies of self-compatible species and of species capable of autonomous seed set among our invasive species from the frequencies in the global data sets with two-tailed $\chi^{2}$. squared tests or, when some of the raw counts in a cell were $<5$, with Fisher's exact-probability tests (statistical software: VassarStats; http://faculty/vassar.edu/lowry/ VassarStats.html).

To test whether the degree of autonomous seed production of the 12 species in our breeding-system experiments is associated with size of the invaded range in China, we calculated the Pearson correlation coefficient between the number of Chinese provinces in which the species occurs and proportion seed set on bagged capitula (statistical software: R, version 2.9.1; R Development Core Team 2009). For the 36 invasive Asteraceae in China for which we collected breeding-system data from the literature, we used
Tukey's multiple-comparison tests to test whether the number of Chinese provinces differs significantly at $P<0.05$ between self-incompatible, partially selfincompatible, self-compatible and apomictic species (statistical software: JMP 7.0; SAS Institute Inc., Cary, NC, USA).

\section{Results}

Breeding systems of invasive Asteraceae in China

Ten of the 12 invasive species of Asteraceae in our breeding-system experiments were capable of seed production when pollinators were excluded with paper bags (for all ten species seed set was $>40 \%$; Fig. 1). Two of the ten species with autonomous seed set, Ageratina adenophora and Erigeron annuus, had similar seed set on decapitated capitula as on bagged capitula (seed set $>40 \%$; Fig. 1), indicating that these two species are highly apomictic, and that the other

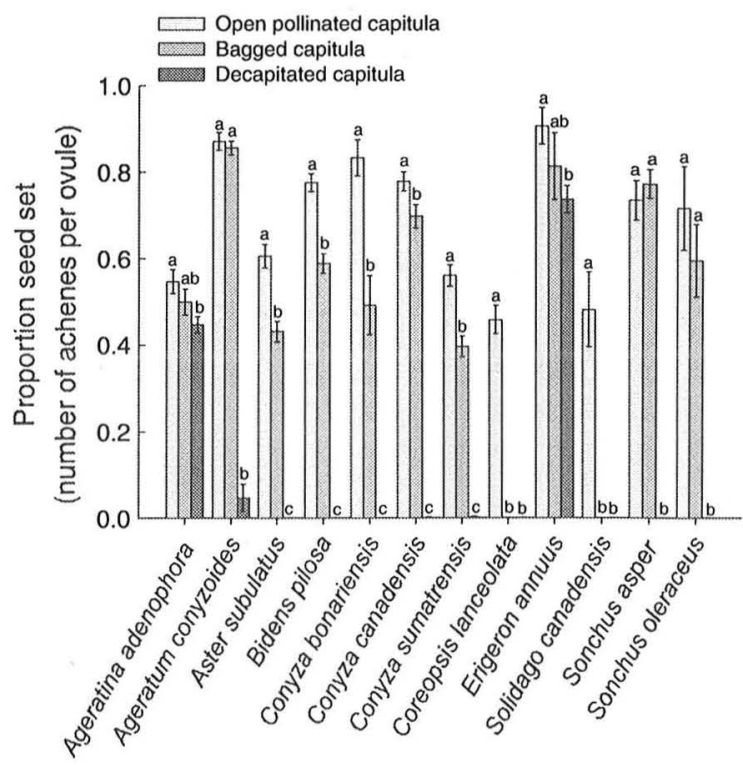

Fig. 1 Mean $( \pm$ SE) seed set of 12 invasive alien species of Asteraceae in China for open pollinated, bagged and decapi tated capitula. Seed set was measured as the number of seeds divided by the number of ovules per capitula. Seed set on bagged capitula indicates autonomous seed set, and seed set on decapitated capitula indicates apomixis. Significant differences $(P<0.05$; based on Tukey multiple comparisons tests) in seed set between treatments are indicated by different letters above the bars for each species separately 
eight species are autogamous and thus self-compatible. In addition, one of the autogamous species, Ageratum conyzoides, also showed a low degree of apomixis (Fig. 1).

Microscopy showed that self-pollen of the two highly apomictic species did not develop on their stigmas, indicating that they are self-incompatible or have low pollen viability. For the two species not capable of autonomous seed set, Coreopsis lanceolata and Solidago canadensis, self-pollen also did not develop on their stigmas, indicating that they are also self-incompatible. On the other hand, for the three species capable of autonomous seed set, Bidens pilosa, Sonchus asper and S. oleraceus, tubes of self-pollen grew into their styles, confirming selfcompatibility of these species.

Breeding systems of species of Asteraceae invasive in China and of those in global data sets

Ferrer and Good-Avila (2007) reported data on selfcompatibility of 571 Asteraceae from around the world of which 361 species $(63.2 \%)$ were categorized as strictly self-incompatible. The others are fully (154 species) or partially self-compatible (56 species). Among our 12 species of Asteraceae that are invasive in China, the percentage of self-compatible species $(66.7 \%)$ was significantly higher than expected from the percentage of fully and partially self-compatible species in the global data set of Ferrer and GoodAvila (36.8\%; Fisher exact test, $P=0.040)$. For the invasive Asteraceae in China for which we found breeding-system data in the literature, the percentage of self-compatible species $(65.7 \%)$ was also significantly higher than expected from the global data set of Ferrer and Good-Avila $\left(\chi^{2}=11.67, d f=1\right.$, $P=0.0006)$.

Fryxell (1957) reported breeding system information on 139 Asteraceae from around the world of which 75 species $(54.0 \%)$ were categorized as strictly self-incompatible (i.e. not capable of autonomous seed-set). Among our 12 species of Asteraceae that are invasive in China, the percentage of species capable of autonomous seed set $(83.3 \%)$ was significantly larger than expected from the percentage of such species in the global data set of Fryxell (46.0\%; Fisher exact test, $P=0.016)$.

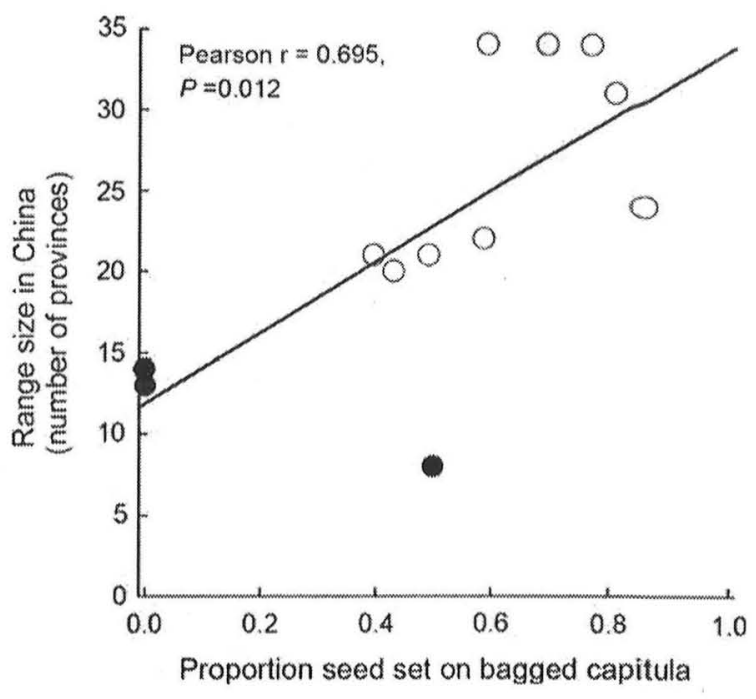

Fig. 2 Correlation between degree of autonomous seed set (i.e. seed set on bagged capitula) and invaded range size of 12 invasive alien species of Asteraceae in China. Open symbols are annual species, and closed symbols are perennial species

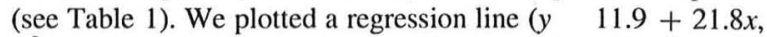
$R^{2} \quad 0.48$ ) to emphasize the significant positive correlation

Degree of autonomous seed set and spread of invasive species in China

The number of Chinese provinces in which the 12 invasive alien species used in our breeding-system experiments occur was significantly positively correlated with the proportion seed set on bagged capitula ( $r=0.695, \quad P=0.012$; Fig. 2). Among the 36 invasive alien species for which we found breedingsystem data in the literature, self-incompatible species occurred in the smallest number of provinces whereas the fully self-compatible species occurred in the largest number of provinces (Fig. 3).

\section{Discussion}

We assessed breeding systems of 12 species of Asteraceae that are invasive in China to test whether as predicted from Baker's Law (Baker 1955) self-compatibility and ability for autonomous seed set are associated with invasiveness. We found that ten of the 12 species are capable of autonomous seed set when pollinators were excluded. In two of the species, autonomous seed set was solely through apomixis, in seven species solely through autogamy, 


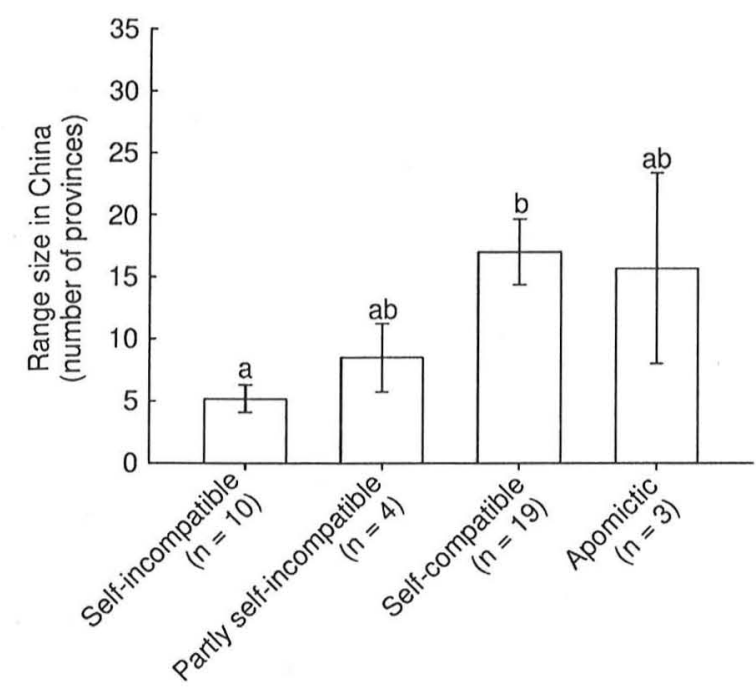

Fig. 3 Mean \pm SE number of invaded provinces in China for self incompatible, partially self incompatible, self compatible and apomictic species of Asteraceae. Significant differences ( $P<0.05$; based on Tukey multiple comparisons tests) between species of different breeding system categories are indicated by different letters above the bars

and in one species through both mechanisms. The two species without autonomous seed set, Coreopsis lanceolata and Solidago canadensis, were self-incompatible. These two species are, however, capable of vegetative reproduction through vigorous rhizomatous growth. The breeding systems that we inferred from our experiments largely confirmed information that we found in the literature on self-compatibility and apomixis of the 12 species (Table 1), but added important information of the capacity for autonomous seed production. Overall, our results indicate that all 12 study species are capable of uniparental reproduction of some form, and that in most of these species this is through autonomous seed production.

On the basis of Baker's Law, we predicted that selfcompatible species, and particularly those capable of autonomous seed production, should have a higher chance to become invasive than self-incompatible species. Therefore, the frequency of self-compatible species and of species capable of autonomous seed set should be higher among invasive species than among the potential source flora (Rambuda and Johnson 2004). Indeed, among our 12 species of Asteraceae that are invasive in China, the frequencies of self-compatibility and autonomous seed set were higher than the corresponding frequencies in global data sets of
Asteraceae. Similarly, among the 36 species of Asteraceae that are invasive in China and for which we found breeding-system data in the literature, the frequency of self-compatible species was also higher than expected. Although we do not have information on whether all species of Asteraceae in these global data sets have had the opportunity to become invasive in China (i.e. whether they have been introduced to China), these results are in line with the predictions of Baker's Law. Similarly, Rambuda and Johnson (2004) found that among 17 invasive alien species in South Africa, all were capable of autonomous seed set. Furthermore, van Kleunen et al. (2008) found that among 20 SouthAfrican species of Iridaceae, the ones capable of autonomous seed set were more likely to naturalize after introduction elsewhere in the world. Overall, our results add to the evidence that self-compatibility and autonomous seed set increase the likelihood of establishment after introduction.

Baker's Law would also predict that among the species that have become invasive, the ones capable of autonomous seed set should be more widely spread (van Kleunen and Johnson 2007). Indeed, among our 12 species of invasive alien Asteraceae in China, the number of provinces in which a species occurs was positively associated with seed set on bagged capitula. Furthermore, among the 36 species of Asteraceae that are invasive in China and for which we found breedingsystem data in the literature, self-compatible species were more widespread than self-incompatible species. This indicates that autonomous seed set is not only associated with initial establishment of an alien species of Asteraceae in China but also with its subsequent spread. Similarly, van Kleunen and Johnson (2007) reported that among 361 European species naturalized in North America, the ones capable of autonomous seed set occur in more USA states. This opposes the findings of Sutherland (2004), who reported that among 142 species, invasive exotic weeds in the USA are less frequently self-compatible than noninvasive ones. This discrepancy could reflect that Sutherland (2004) used a categorical variable (invasive vs. non-invasive) instead of a continuous one (number of USA states), and that it was biased towards inclusion of invasive species that are perennials, particularly shrubs and trees, which are more frequently selfincompatible than annuals (Lloyd and Schoen 1992; Barrett et al. 1996). Other recent studies, however, found that among alien introduced species, the ones 
capable of autonomous seed set are more widespread (Küster et al. 2008; Lambdon et al. 2008). Overall, our results add to the evidence that self-compatibility and autonomous seed set might promote spread of plant species.

Although our results and the results of previous studies (e.g. Rambuda and Johnson 2004; van Kleunen and Johnson 2007; Küster et al. 2008; Lambdon et al. 2008; van Kleunen et al. 2008) suggest that the ability for autonomous seed set might contribute to invasion success, we cannot exclude the possibility that other species traits that are frequently associated with autonomous seed set are the real determinants of invasiveness. For example, selffertilization is frequently associated with an annual life-cycle (e.g. Lloyd and Schoen 1992; Barrett et al. 1996). Because annual species are frequently prevalent among invasive species, particularly as ruderals in areas disturbed by humans (e.g. Mulligan and Findlay 1970; Pyšek et al. 1995), it is well possible that other characteristics associated with annual species are the ultimate determinants of invasiveness. In our study, there were nine annual species, and all were capable of autonomous seed set. On the other hand, two of the three perennial species were selfincompatible. Nevertheless, among the nine invasive annual species in our study, the size of the invaded range in China was positively associated with the degree of autonomous seed set (Fig. 2), although this was not significant $(r=0.603, P=0.086)$. Similarly, van Kleunen and Johnson (2007) showed that among monocarpic species (mostly annual and biennial species) in their data set of European species, the ones capable of autonomous seed set had larger invaded ranges in North America than the ones not capable of autonomous seed set. Therefore, we conclude that the association of autonomous seed set with invasion success is, at least partly, independent of the life-cycle of the species.

Current spread of the invasive species of Asteraceae in China might not only be affected by species characteristics such as the breeding system and lifecycle, but also by the time since introduction. Accurate data for the year of introduction are not available for most of the species in our study, but we have some information on the time of first record in China (Appendix S2 Electronic supplementary material). As one might expect, species that were recorded before 1,900 occurred in more provinces (mean \pm SE: $27.6 \pm 2.2, n=8$ ) than species that were recorded after $1,900(9.9 \pm 1.6, n=23$; $t$-test: $t=6.55, d f=15.2, P<0.001)$. Consequently, the association between the breeding system and spread in China is not significant if one includes time of first record in the statistical models (results not shown). However, because invasive, widespread species are more likely to be collected than less widespread species, time of first record might simply reflect invasiveness of the species rather than time of introduction (Bucharova and van Kleunen 2009). If the time of first record would correctly reflect the time of introduction, our results would indicate that self-compatible species and species with autonomous seed production were introduced earlier than selfincompatible species and species without autonomous seed production. Because there are no specific reasons to expect such a biased introduction, we think that this is a less likely explanation of our results than that self-compatibility and autonomous seed production contribute to invasiveness of alien plant species.

\section{Implications for risk assessment}

For prevention and management of plant invasions, identification of invasive species based on functional traits is an indispensable cornerstone of designing protocols for risk-assessment of species considered for introduction (Groves et al. 2001). Based on theoretical considerations, such as the ones behind Baker's Law (Baker 1955), many weed-risk assessment protocols like the Australian Weed Risk Assessment (Pheloung et al. 1999) include already the breeding system of plants. However, the empirical basis for considering breeding systems for riskassessment was still relatively weak. Our study and other recent studies (Rambuda and Johnson 2004; van Kleunen and Johnson 2007; Küster et al. 2008; Lambdon et al. 2008; van Kleunen et al. 2008) provide empirical support for the inclusion of the breeding system as one of the key elements in risk assessment protocols for plant invasiveness.

Acknowledgments This research was supported by National Basic Research and Development Program (2009CB1 192) and Special Scientific Research Program for Non profit Profession (No. 200709017). We thank Sara Good Avila for providing us with data on the breeding systems of a global set of Asteraceae, Shu Shun Li, Lu Ren and Yan Chen for their assistance during the experiments or making plates, and the editor and two 
anonymous reviewers for helpful comments on an earlier version of the manuscript. TC and MvK are supported by the Swiss Science Foundation (SNF), grant no. 31003A 117722. MvK also acknowledges support by the Sino Swiss Science and Technology Cooperation.

\section{References}

Auld BA, Martin PM (1975) Autecology of Eupatorium ade nophorum Spreng. in Australia. Weed Res 15:27 31

Baker HG (1955) Self compatibility and establishment after 'long distance' dispersal. Evolution 9:347 349

Baker HG (1965) Characteristics and modes of origin of weeds. In: Baker HG, Stebbins GL (eds) The genetics of colonizing species. Academic Press, New York, pp 147172

Barrett SCH, Harder LD, Worley AC (1996) The comparative biology of pollination and mating in flowering plants. Phil Trans Roy Soc Lond B 351:1271 1280

Bertin RI (1993) Incidence of monoecy and dichogamy in relation to self fertilization in angiosperms. Am J Bot $80: 557560$

Brennan AC, Harris SA, Tabah DA, Hiscock SJ (2002) The population genetics of sporophytic self incompatibility in Senecio squalidus L. (Asteraceae) I: S allele diversity in a natural population. Heredity 89:430 438

Bucharova A, van Kleunen M (2009) Introduction history and species characteristics partly explain naturalization suc cess of North American woody species in Europe. J Ecol 97:230 238

Colautti RI, Grigorovich IA, MacIsaac HJ (2006) Propagule pressure: a null model for biological invasions. Biol Invas 8:1023 1037

Cronk QCB, Fuller JL (2001) Plant invaders. Earthscan, London

Currier HB (1957) Callose substance in plant cells. Am J Bot $44: 478 \quad 482$

Daehler CC (1998) The taxonomic distribution of invasive angiosperm plants: ecological insights and comparison to agricultural weeds. Biol Conserv 84:167 180

Daehler CC (2003) Performance comparisons of co occurring native and alien invasive plants. Ann Rev Ecol Syst $34: 183211$

Daehler CC, Strong DR (1993) Prediction and biological invasion. Trends Ecol Evol 8:380

Ferrer MM, Good Avila SV (2007) Macrophylogenetic anal yses of the gain and loss of self incompatibility in the Asteraceae. New Phytol 173:401 414

Fryxell PA (1957) Mode of reproduction of higher plants. Bot Rev 23:135 233

Grombone Guaratini MT, Solferini VN, Semir J (2004) Reproductive biology in species of Bidens L. (Astera ceae). J Sci Food Agric 61:185 189

Groves RH, Panetta FD, Virtue JG (2001) Weed risk assess ment. CSIRO Publishing, Collingwood

Hao JH, Qiang S, Liu QQ, Cao F (2009) Reproductive traits assotiated with invasiveness in Conyza sumatrensis. J Plant Syst Evol 47:245 254
Hiscock SJ (2000) Self incompatibility in Senecio squalidus L. (Asteraceae). Ann Bot 85SA:181 190

Hong L, Shen H, Ye WH, Cao HL, Wang ZM (2007) Self incompatibility in Mikania micrantha in South China. Weed Res 47:280 283

Hutchinson I, Colosi J, Lewin RA (1984) The biology of Canadian weeds. 63. Sonchus asper (L.) hill and Sonchus oleraceus L. Can J Plant Sci 64:731 744

Küster EC, Kühn I, Bruelheide H, Klotz S (2008) Trait inter actions help explain plant invasion success in the German flora. J Ecol 96:860 868

Lafuma L, Maurice S (2007) Increase in mate availability without loss of self incompatibility in the invasive species Senecio inaequidens (Asteraceae). Oikos 116:201 208

Lambdon PW, Lloret F, Hulme PE (2008) How do introduction characteristics influence the invasion success of mediter ranean alien plants? Perspect Plant Ecol 10:143 159

Lloyd DG, Schoen DJ (1992) Self and cross fertilization in plants. I. Functional dimensions. Int J Plant Sci 153:358 369

Lockwood JL, Cassey P, Blackburn T (2005) The role of propagule pressure in explaining species invasions. Trends Ecol Evol 20:223 228

Mason RAB, Cooke J, Moles AT, Leishman MR (2008) Reproductive output of invasive versus native plants. Glob Ecol Biogeog 17:633 640

McMullen CK (1987) Breeding systems of selected Galapagos Islands angiosperms. Am J Bot 74:1694 1705

Mejias JA (1992) Reproductive biology in the Iberian taxa of the genera Sonchus and Aetheorhiza (Asteraceae: Lactu ceae). Flor Mediter 2:5 24

Melvillme R, Morton JK (1982) A biosystematic study of the Solidago canadensis (Compositae) complex. I. The Ontario populations. Can J Bot 60:976 997

Ming LC (1999) Ageratum conyzoides: a tropical source of medicinal and agricultural products. In: Janick $\mathbf{J}$ (ed) Perspectives of new crops and new uses. ASHS Press, Alexandria, pp 469473

Mooney HA, Mack RN, McNeely JA, Neville LE, Schei PJ, Waage JK (2005) Invasive alien species: a new synthesis. Island Press, Washington, DC

Mulligan GA, Findlay N (1970) Reproductive systems and colonization in Canada weeds. Can J Bot 48:859 860

Nogler GA (1984) Gametophytic apomixis. In: Johri BM (ed) Embryology of angiosperms. Springer, Berlin, pp 474518

Noyes RD, Rieseberg LH (2000) Two independent loci control agamospermy in the triploid flowering plant Erigeron annuus. Genetics 155:379 390

Pannell JR, Barrett SCH (1998) Baker's law revisited: reproduc tive assurance in a metapopulation. Evolution 52:657 668

Pheloung PC, Williams PA, Halloy SR (1999) A weed risk assessment model for use as a biosecurity tool evaluating plant introductions. J Environ Manage 57:239 251

Pullaiah T (1982) Studies in the embryology of compositae. II. The tribe Eupatorieae. Eupatorium odoratum, Ageratum conyzoides. Ind J Bot 5:183 188

Pyšek P (1998) Is there a taxonomic pattern to plant invasions? Oikos 82:282 294

Pyšek P, Richardson DM (2007) Traits associated with inva siveness in alien plants: where do we stand? In: Nentwig W (ed) Biological invasions. Section II. Springer, Berlin, pp 97125 
Pyšek P, Prach K, Šmilauer P (1995) Relating invasion success to plant traits: an analysis of the Czech alien flora. In: Pyšek P, Prach K, Rejmánek M, Wade M (eds) Plant invasions general aspects and special problems. SPB Academic Publishing, Amsteradam, pp 3960

Rambuda TD, Johnson SD (2004) Breeding systems of inva sive alien plants in South Africa: does baker's rule apply? Divers Distrib 10:409 416

Rejmánek M (1996) A theory of seed plant invasiveness: the first sketch. Biol Conserv 78:171 181

Rejmánek M, Richardson DM (1996) What attributes make some plant species more invasive? Ecology 77:1655 1661

Richardson DM, Pyšek P (2006) Plant invasions: merging the concepts of species invasiveness and community invasi bility. Progr Phys Geog 30:409 431

Richardson DM, Pyšek P, Rejmánek M, Barbour MG, Panetta FD, West CJ (2000) Naturalization and invasion of alien plants: concept and definitions. Divers Distrib 6:93 107

R Development Core Team (2009) R: a language and envi ronment for statistical computing. $\mathrm{R}$ foundation for sta tistical computing, Vienna, ISBN 390005107 0, URL http://www.R project.org

Rodger JG, van Kleunen M, Johnson SD (2010) Is specialised pollination an impediment to invasion? Int J Plant Sci 171:382 391

Stebbins GL (1957) Self fertilization and population variation in the higher plants. Am Nat 91:337 354

Sun M, Ritland K (1998) Mating system of yellow starthistle (Centaurea solstitialis), a successful colonizer in North America. Heredity 80:225 232

Sutherland S (2004) What makes a weed a weed: life history traits of native and exotic plants in the USA. Oecologia 141:24 39 van Kleunen M, Johnson SD (2005) Testing for ecological and genetic allee effects in the invasive shrub Senna didy mobotrya (Fabaceae). Am J Bot 92:1124 1130

van Kleunen M, Johnson SD (2007) Effects of self compati bility on the distribution range of invasive European plants in North America. Conserv Biol 21:1537 1544

van Kleunen M, Richardson DM (2007) Invasion biology and conservation biology time to join forces to explore the links between species traits and extinction risk and inva siveness. Progr Phys Geog 31:447 450

van Kleunen M, Manning JC, Pasqualetto V, Johnson SD (2008) Phylogenetically independent associations between autonomous self fertilization and plant inva siveness. Am Nat 171:195 201

van Kleunen M, Weber E, Fischer M (2010) A meta analysis of trait differences between invasive and non invasive plant species. Ecol Lett 13:235 245

Weaver SE (2001) The biology of Canadian weeds. 115. Conyza canadensis. Can J Plant Sci 81:867 875

Weber E, Guo S G, Li B (2008) Invasive alien plants in China: diversity and ecological insights. Biol Invas 10: 14111429

Werner PA, Bradbury IK, Gross RS (1980) The biology of Canadian weeds. 45. Solidago canadensis L. Can J Plant Sci 60:1393 1409

Wu SH, Wang HH (2005) Potential Asteraceae invaders in Taiwan: insights from the flora and herbarium records of casual and naturalized alien species. Taiwania 50:62 70

Xu HG, Qiang S (2004) Inventory of invasive alien species in China. China Environmental Science Press, Beijing

Zhu SX, Qin HN, Chen Y (2005) Alien species of compositae in China. Guihaia 25:69 76 